\title{
Hypoxic hepatitis in cardiac intensive care unit: a study of cardiovascular risk factors, clinical course, and outcomes
}

This article was published in the following Dove Press journal:

Therapeutics and Clinical Risk Management

25 February 2014

Number of times this article has been viewed

\author{
Norberto C Chávez-Tapia' \\ Brenda $\vee$ Balderas-Garces' \\ Patricia Meza-Meneses' \\ Magali Herrera-Gomar² \\ Sandra García-López ${ }^{2}$ \\ Octavio Gónzalez-Chon ${ }^{2}$ \\ Misael Uribe' \\ 'Obesity and Digestive Diseases Unit, \\ ${ }^{2}$ Coronary Care Unit, Medica Sur \\ Clinic and Foundation, Mexico City, \\ Mexico
}

Introduction: Hypoxic hepatitis $(\mathrm{HH})$ is observed frequently in intensive care units. Information in the cardiac intensive care unit (CICU) is limited. The aim of this study was to analyze the clinical course and outcomes of $\mathrm{HH}$ in the specific setting of the CICU.

Methods: We analyzed records of patients with HH admitted to the CICU (Group 1). Data were collected and compared with those of an intermediate group of patients with altered liver test results that did not meet the $\mathrm{HH}$ criteria who had a serum aminotransferase level of five to $\leq 20$ times the upper-normal limit (Group 2), and with a control group who had an aminotransferase level less than five times the upper-normal limit (Group 3).

Results: Patients with HH exhibited a worse hemodynamic profile and more of these patients were in shock: 17 (94.4\%) in Group 1, 14 (77.8\%) in Group 2, and seven (38.9\%) in Group 3 $(P=0.001)$. Cardiogenic shock was the most frequent event: 12 (66.7\%) in Group 1, $13(72.2 \%)$ in Group 2, and six (33.3\%) in Group $3(P=0.006)$. The mortality rate was $55.6 \%$. Mechanical ventilation was an independent factor associated with death (odds ratio $12.25,95 \%$ confidence interval 1.26-118.36).

Conclusion: The mortality rate of patients with $\mathrm{HH}$ in CICU is high and is associated with ventilatory disturbances.

Keywords: liver dysfunction, mechanical ventilation, hospital mortality

\section{Introduction}

Hypoxia is the cornerstone of hypoxic hepatitis $(\mathrm{HH})$, a state that can be caused by heart or pulmonary failure or septic shock. ${ }^{1}$ The prevalence of $\mathrm{HH}$ ranges from $0.9 \%$ to $11.9 \%$; the variation in this range can be explained by the characteristics of the clinical setting. ${ }^{2}$ The low prevalence precludes identifying specific characteristics in subgroups of patients with HH. Moreover, the aminotransferase level required to make a diagnosis of $\mathrm{HH}$ is not clear; in some series, it is five times the upper-normal limit, and in others, it is 75 times the upper-normal limit. For this reason, there are no uniform criteria for making the diagnosis.

$\mathrm{HH}$ has clinical relevance because of the high in-hospital mortality of around $50 \%{ }^{2}$ Various risk factors associated with the high mortality rate in $\mathrm{HH}$ patients have been postulated: high levels of serum aspartate aminotransferase (AST), lactate dehydrogenase, or lactate; the International Normalized Ratio; and the presence of septic shock. ${ }^{3}$ Renal replacement therapy and use of vasopressor therapy have also been reported as mortality risk factors. ${ }^{4}$

There is little information about the specific settings associated with $\mathrm{HH}$, such as the cardiac intensive care unit (CICU). Some differences have been reported. For
Correspondence: Norberto C ChávezTapia

Obesity and Digestive Diseases Unit, Medica Sur Clinic and Foundation, Puente de Piedra 150, Col Toriello Guerra, Tlalpan 14050, Mexico City, Mexico Email nchavezt@medicasur.org.mx 
example, HH patients present with high central venous pressure (CVP) and low hepatic blood flow. ${ }^{5}$ More recent data show that patients with an acute myocardial lesion have an elevated aminotransferase level, which correlates with right cardiac dysfunction and elevated hepatic venous pressure. ${ }^{6}$ The specific characteristics of this setting suggest that $\mathrm{HH}$ may follow different courses, but information is scarce.

The primary aim of this study was to analyze the clinical course and outcomes of $\mathrm{HH}$ in the specific setting of a cardiac intensive care unit. The secondary aim was to compare these variables between patients without $\mathrm{HH}$ but with significantly altered liver function and $\mathrm{HH}$ patients treated in a cardiac intensive care unit.

\section{Materials and methods}

A retrospective case-control study was performed in the cardiac intensive care unit of the Medica Sur Clinic and Foundation university hospital from 2008 to 2011. Three groups of patients were included in the study. Group 1 comprised patients diagnosed with $\mathrm{HH}$ with a serum aminotransferase level $>20$ times the upper-normal limit within the clinical context of cardiac arrest, shock, or acute heart failure. Group 2 included patients with a significant alteration in liver function, defined as a serum aminotransferase level of five to $\leq 20$ times the upper-normal limit (Group 2). Group 3 comprised a control group of patients with an aminotransferase level less than five times the uppernormal limit (Group 3). The patients with significantly altered liver function and the control group were hospitalized in the same cardiac intensive care unit and were matched for sex and age. The exclusion criteria included infection with hepatitis virus, use of drugs with demonstrated hepatotoxicity, or abdominal trauma.

Demographic and clinical information were extracted from paper-based and electronic files. The diagnosis at admission to the cardiac intensive care unit, characteristics of shock, and use of vasopressors were recorded. The results of the liver function tests (levels of AST, alanine aminotransferase, total bilirubin, direct bilirubin, alkaline phosphatase, and gamma-glutamyl transpeptidase) were recorded at baseline, and the highest values reported during hospitalization in the cardiac intensive care unit were recorded.

Hemodynamic status was analyzed through the following variables: mean blood pressure; CVP; cardiac output; cardiac index; systemic vascular resistance index; systolic volume; and systolic volume index. ${ }^{7}$

Myocardial function was analyzed by echography and the following data were recorded: left ventricular ejection frac- tion calculated by Simpson's rule and the Teichholz formula; fractional area shortening; left and right ventricular myocardial performance indexes; lateral and medial mitral annular tissue Doppler velocities; pulsed-wave tissue Doppler velocity of the tricuspid annular plane systolic excursion (TAPSE); mean pulmonary artery pressure; right ventricular ejection fraction; tissue Doppler E/E' ratio; and cardiac output. ${ }^{8}$ Serum B-type natriuretic peptide concentration was also measured as a marker of heart failure. ${ }^{9}$

Ventilation was assessed by measuring arterial blood gases: carbon dioxide arterial pressure; oxygen arterial pressure; oxygen saturation; lactate concentration; Kirby index; arteriovenous shunt; and alveolar-arterial $\mathrm{O}_{2}$ gradient. ${ }^{10}$

Renal dysfunction was defined as high blood urea nitrogen or serum creatinine concentration, or the need for therapy (peritoneal dialysis or hemodialysis). ${ }^{11}$

The study was approved by the Human Subjects Committee of the Medica Sur Clinic and Foundation as conforming to the ethical guidelines of the 1975 Declaration of Helsinki. Consent was obtained from all patients to analyze their data for research. All participants signed a written informed consent to allow the use of their data for research purposes.

\section{Statistical analysis}

The variables are described by measures of central tendency and dispersion. Continuous variables were compared using analysis of variance and the Bonferroni post hoc test for multiple comparisons. Categorical data were compared using Fisher's exact test or the $\chi^{2}$ test. To identify risk factors associated with mortality, multivariate unconditional logistic regression analyses were conducted. Multicollinearity in the adjusted models was tested by deriving a covariance matrix. To discriminate those factors associated with mortality, the area under the curve was calculated. A $P$-value $<0.05$ was considered significant. All statistical analyses were conducted using the statistics program SPSS/PC version 12.0 (IBM Corporation, Armonk, NY, USA).

\section{Results}

During the analyzed period, 1,649 patients were admitted to the cardiac intensive care unit. Eighteen cases of $\mathrm{HH}$ were identified, with a prevalence of $1.09 \%$. There were no differences between the groups in demographics, diagnosis, and morbid conditions (Table 1). Most patients with HH developed shock, defined as a mean arterial pressure $<65 \mathrm{mmHg}$, lack of response to fluid resuscitation, and the need for vasopressors to maintain mean arterial pressure above this value. Seventeen (94.4\%) patients in Group 1, 14 (77.8\%) patients 
Table I Demographic and clinical characteristics of patients in the cardiac intensive care unit

\begin{tabular}{|c|c|c|c|c|}
\hline & Group I $(n=\mid 8)$ & Group $2(n=18)$ & Group $3(n=18)$ & $P$-value \\
\hline Male n (\%) & $12(66.7 \%)$ & $12(66.7 \%)$ & $12(66.7 \%)$ & 1 \\
\hline Age (years) & $61 \pm 17$ & $61 \pm 17$ & $60 \pm 17$ & 0.998 \\
\hline Body mass index $\left(\mathrm{kg} / \mathrm{m}^{2}\right)$ & $27 \pm 5$ & $29 \pm 6$ & $27 \pm 6$ & 0.374 \\
\hline Diabetes mellitus $\mathrm{n}(\%)$ & $5(27.8 \%)$ & $4(22.2 \%)$ & 7 (38.9\%) & 0.53 \\
\hline High blood pressure $\mathrm{n}(\%)$ & 7 (38.9\%) & II (6I.1\%) & 8 (44.4\%) & 0.38 \\
\hline Heart failure n (\%) & 0 & I (5.6\%) & I (5.6\%) & 0.59 \\
\hline Cardiovascular disease n (\%) & $5(27.8 \%)$ & 7 (38.9\%) & $6(33.3 \%)$ & 0.77 \\
\hline Chronic liver disease $n(\%)$ & $2(11.1 \%)$ & 0 & I (5.6\%) & 0.34 \\
\hline Chronic lung disease $n(\%)$ & I (5.6\%) & $2(11.1 \%)$ & I (5.6\%) & 0.76 \\
\hline Chronic kidney disease $\mathrm{n}(\%)$ & I (5.6\%) & $3(16.7 \%)$ & $3(16.7 \%)$ & 0.51 \\
\hline \multicolumn{5}{|l|}{ Diagnosis } \\
\hline Myocardial infarction n (\%) & $8(44.4 \%)$ & II (6I.I\%) & 7 (38.9\%) & 0.308 \\
\hline Cardiac arrhythmia n (\%) & $3(16.8 \%)$ & $\mathrm{I}(5.6 \%)$ & I (5.6\%) & \\
\hline Acute aortic syndrome $\mathrm{n}(\%)$ & I (5.6\%) & 0 & $3(16.7 \%)$ & \\
\hline Acute heart failure $\mathrm{n}(\%)$ & 0 & $3(16.7 \%)$ & I (5.6\%) & \\
\hline Pulmonary embolism n (\%) & $2(11.1 \%)$ & I (5.6\%) & I (5.6\%) & \\
\hline Tamponade $\mathrm{n}(\%)$ & $3(16.7 \%)$ & 0 & I (5.6\%) & \\
\hline Hospital stay (days) & $8 \pm 5$ & $8 \pm 5$ & $8 \pm 6$ & 0.990 \\
\hline Intensive care unit stay (days) & $4 \pm 2$ & $5 \pm 3$ & $4 \pm 4$ & 0.470 \\
\hline Mortality n (\%) & $10(55.6 \%)$ & $6(35.3 \%)$ & $2(11.1 \%)$ & 0.019 \\
\hline
\end{tabular}

Note: Data are expressed as mean \pm standard deviation or $\mathrm{n}(\%)$.

in Group 2, and seven (38.9\%) patients in Group $3(P=0.001)$ developed shock (Table 2). The most common cause of shock was cardiogenic shock, defined as a systolic blood pressure of $<90 \mathrm{mmHg}$ for $>30$ minutes secondary to myocardial dysfunction, cardiac index $<2.2 \mathrm{~L} / \mathrm{min} / \mathrm{m}^{2}$, or pulmonary capillary wedge pressure $>15 \mathrm{mmHg}$. Cardiogenic shock was less common in Group 3; 12 (66.7\%) patients in Group 1, 13 (72.2\%) patients in Group 2, and six (33.3\%) patients in Group $3(P=0.006)$ developed cardiogenic shock. The use of vasoactive drugs differed between the groups, particularly for norepinephrine (16 [88.9\%] patients in Group 1, 14 [77.8\%] patients in Group 2, and seven [38.9\%] patients in

Table 2 Hemodynamic status, hemodynamic drugs, and echocardiographic parameters

\begin{tabular}{|c|c|c|c|c|c|}
\hline & Total $(n=54)$ & Group I $(n=18)$ & Group $2(n=18)$ & Group $3(n=18)$ & $P$-value \\
\hline Shock & $38(70.4)$ & $17(94.4)$ & $14(77.8)$ & $7(38.9)$ & 0.001 \\
\hline Cardiogenic shock & $31(57.4)$ & $12(66.7)$ & $13(72.2)$ & $6(33.3)$ & \\
\hline Septic shock & $3(5.6)$ & $2(11.1)$ & I (5.6) & 0 & 0.006 \\
\hline Mixed shock & $4(7.4)$ & $3(16.7)$ & 0 & I (5.6) & \\
\hline Dopamine & $19(35.2)$ & $8(44.4)$ & $6(33.3)$ & $5(27.8)$ & 0.566 \\
\hline Norepinephrine & $37(68.5)$ & $16(88.9)$ & I4 (77.8) & $7(38.9)$ & 0.003 \\
\hline Vasopressin & $27(50)$ & $12(66.7)$ & $10(55.6)$ & $5(27.8)$ & 0.056 \\
\hline Epinephrine & $9(16.7)$ & $3(16.7)$ & $5(27.8)$ & I (5.6) & 0.202 \\
\hline Levosimendan & $33(61.1)$ & $13(72.2)$ & $13(72.2)$ & $7(38.9)$ & 0.060 \\
\hline Phenylephrine & II (20.4) & $8(44.4)$ & $2(11.1)$ & I (5.6) & 0.007 \\
\hline Dobutamine & $4(7.4)$ & I (5.6) & I (5.6) & $2(I I . I)$ & 0.763 \\
\hline Intra-aortic balloon pump & $10(18.5)$ & $4(22.2)$ & $4(22.2)$ & $2(11.1)$ & 0.612 \\
\hline CVP lowest $\left(\mathrm{cmH}_{2} \mathrm{O}\right)^{\mathrm{a}}$ & & $8 \pm 5 *$ & $6 \pm 5$ & $2 \pm 5$ & 0.006 \\
\hline $\mathrm{CO}$ lowest $(\mathrm{L} / \mathrm{min})^{\mathrm{a}}$ & & $4.1 \pm 2.1$ & $3.5 \pm 1.8$ & $4.9 \pm 2.3$ & 0.704 \\
\hline MAP lowest (mmHg) & & $54 \pm 15$ & $58 \pm 14$ & $59 \pm 14$ & 0.602 \\
\hline SAP lowest (mmHg) & & $73 \pm 25$ & $83 \pm 15$ & $87 \pm 20$ & 0.112 \\
\hline $\mathrm{Cl}$ lowest $\left(\mathrm{L} / \mathrm{min} / \mathrm{m}^{2}\right)^{\mathrm{a}}$ & & $2.3 \pm 1.1$ & $1.6 \pm 0.9$ & $2.7 \pm 1.2$ & 0.429 \\
\hline TAPSE (mm) & & $15 \pm 6 *$ & $18 \pm 4$ & $22 \pm 6$ & 0.035 \\
\hline EF LV by Teichholz formula (\%) & & $52 \pm 18$ & 56 & $59 \pm 21$ & 0.863 \\
\hline EF LV by Simpson's rule (\%) ${ }^{\mathrm{a}}$ & & $4 I \pm 15$ & $45 \pm 11$ & $53 \pm 15$ & 0.058 \\
\hline
\end{tabular}

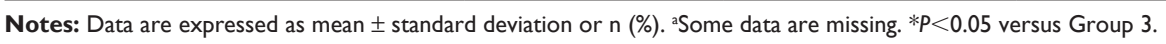

Abbreviations: $\mathrm{Cl}$, cardiac index; CO, cardiac output; CVP, central venous pressure; EF, ejection fraction; LV, left ventricle; MAP, mean arterial pressure; SAP, systolic arterial pressure; TAPSE, tricuspid annular plane systolic excursion. 
Group 3; $P=0.003$ ) and phenylephrine (eight [44.4\%] patients in Group 1, two [11.1\%] patients in Group 2, and one [5.6\%] patient in Group 3; $P=0.007$ ).

The levels of transaminases, lactate dehydrogenase, and bilirubin differed between Groups 1 and 2, and between Groups 1 and 3, but not between Groups 2 and 3 (Table 3).

Hemodynamic variables such as mean arterial pressure, cardiac output, systemic vascular resistance index, systolic volume, and systemic vascular resistance were lower in Group 1 but did not differ between Groups 2 and 3, except for CVP, which was significantly higher in Group 1 compared with Group 3 ( $8 \pm 5 \mathrm{cmH}_{2} \mathrm{O}$ in Group 1, $6 \pm 5 \mathrm{cmH}_{2} \mathrm{O}$ in Group 2, and $2 \pm 5 \mathrm{cmH}_{2} \mathrm{O}$ in Group $3 ; P<0.05$ ) (Table 2). The echocardiographic variables showed a trend toward different left ventricular function between groups. In the assessment of right ventricular function, TAPSE differed significantly between Groups 1 and 3 (15 \pm 6 versus $22 \pm 6 \mathrm{~mm} ; P=0.035$ ).

Evaluation of ventilatory function produced results for only 17 patients in Group 1, 15 in Group 2, and 13 in Group 3 (Table 4). The requirement for ventilatory support was higher in Group 1, which showed worse ventilatory function with shunts $(39 \% \pm 16 \%$ in Group $1,25 \% \pm 11 \%$ in Group 2, and $27 \% \pm 12 \%$ in Group $3 ; P=0.004$ ), oxygen saturation ( $82 \% \pm 16 \%$ in Group 1, 93\% $\pm 6 \%$ in Group 2, and 90\% $\pm 8 \%$ in Group 3; $P=0.026)$, and Kirby index $(93 \pm 73 \mathrm{mmHg}$ in Group 1, $167 \pm 88 \mathrm{mmHg}$ in Group 2, and $125 \pm 82 \mathrm{mmHg}$ in Group 3; $P=0.046)$. Serum lactate concentration was higher in patients with $\mathrm{HH}$ or with altered liver function (8.8 $\pm 6.6 \mathrm{mmol} / \mathrm{L}$ in Group $1,6.6 \pm 4.3 \mathrm{mmol} / \mathrm{L}$ in Group 2, and $2.7 \pm 1.9 \mathrm{mmol} / \mathrm{L}$ in Group 3; $P=0.005)$. The lowest $\mathrm{PaO}_{2}$ values were $67 \pm 27 \mathrm{mmHg}, 118 \pm 84 \mathrm{mmHg}$, and $63 \pm 14 \mathrm{mmHg}$ in Groups 1, 2, and 3, respectively; Group 2 differed significantly from the other two groups $(P=0.009)$.
None of the measures of renal function or the use of replacement therapy with dialysis differed between the groups (Table 5).

The length of stay in the cardiac intensive care unit and hospital did not differ between groups (Table 1). Eighteen patients died during their stay. Most patients who died had $\mathrm{HH} ; 10(55.6 \%)$ died in Group 1, six (35.3\%) died in Group 2, and two (11.1\%) died in Group 3. Factors related to mortality were preexistent chronic liver disease, shock, cardiogenic shock, use of norepinephrine, use of vasopressors, use of an intra-aortic balloon pump, and mechanical ventilation (Table 6). However, in multivariate analysis, only mechanical ventilation was associated with an increased risk of death (odds ratio 12.25, 95\% confidence interval 1.26-118.36; $P<0.001)$. We determined the area under the curve to assess the ventilation variables and found that having a higher arteriovenous shunt was a significant variable associated with death (area under the curve $0.721,95 \%$ confidence interval $0.563-0.879)$.

\section{Discussion}

$\mathrm{HH}$ is a common condition in critically ill patients. The prevalence is around 1 in 1,000 hospital admissions and can be ten times higher in the intensive care unit. Its prevalence is unknown in other critical care settings such as the cardiac intensive care unit, and there is only one study in the literature related to other critical care settings. ${ }^{5}$ The current study adds new information about a condition in a setting with limited information.

Heart failure, respiratory failure, and septic shock account for $>90 \%$ of all $\mathrm{HH}$ cases. Several hemodynamic mechanisms are involved in liver hypoxia. ${ }^{2}$ Heart failure from various etiologies is the main underlying condition in $\mathrm{HH}$, but $\mathrm{HH}$

Table 3 Baseline and maximum levels of aspartate aminotransferase, alanine aminotransferase, and lactic dehydrogenase

\begin{tabular}{|c|c|c|c|c|}
\hline & Group I $(n=18)$ & Group $2(n=18)$ & Group $3(n=18)$ & $P$-value \\
\hline \multirow[t]{2}{*}{ Baseline AST (U/L) } & $\mathrm{I}, 52 \mathrm{I} \pm 2,320^{*}, * *$ & $260 \pm 185$ & $55 \pm 49$ & 0.004 \\
\hline & $45 \mathrm{I}(35-9,597)$ & $281(25-670)$ & $36(14-192)$ & \\
\hline \multirow[t]{2}{*}{ AST $\max (\mathrm{U} / \mathrm{L})$} & $3,275 \pm 3,00 \mid * * *$ & $394 \pm 122$ & $60 \pm 49$ & 0.001 \\
\hline & $2,205.5(1,077-12,261)$ & $376.5(236-670)$ & $43.5(14-192)$ & \\
\hline \multirow[t]{2}{*}{ Baseline ALT (U/L) } & $810 \pm 954 * * *$ & $|59 \pm| 3 \mid$ & $43 \pm 45$ & 0.0001 \\
\hline & $389.5(19-3,215)$ & $106(12-384)$ & $29(9-197)$ & \\
\hline \multirow[t]{2}{*}{$\mathrm{ALT} \max (\mathrm{U} / \mathrm{L})$} & $1,736 \pm 1,378 *, * *$ & $227 \pm 132$ & $44 \pm 44$ & 0.001 \\
\hline & I,394 (502-6,243) & $236(58-443)$ & $29(9-197)$ & \\
\hline \multirow[t]{2}{*}{ Baseline LDH (U/L) } & $2,058 \pm 2,398 * * * *$ & $54 I \pm 355$ & $249 \pm 131$ & 0.001 \\
\hline & I,057 (255-5,264) & $403.5(\mid 75-1,301)$ & $230.5(93-576)$ & \\
\hline \multirow[t]{2}{*}{$\mathrm{LDH} \max (\mathrm{U} / \mathrm{L})$} & $4,425 \pm 3,199 *, * *$ & $831 \pm 310$ & $266 \pm|4|$ & 0.001 \\
\hline & $3,862(1,544-14,679)$ & $864.5(564-1,408)$ & $24 I .5(I I I-576)$ & \\
\hline
\end{tabular}

Notes: Data are expressed as mean \pm standard deviation or median (minimum-maximum). $* P<0.05$ versus Group 2 ; **P<0.05 versus Group 3 .

Abbreviations: AST, aspartate aminotransferase; ALT, alanine aminotransferase; LDH, lactic dehydrogenase. 
Table 4 Evaluation of ventilatory function by group

\begin{tabular}{|c|c|c|c|c|}
\hline & Group I (n=|7) & Group $2(n=15)$ & Group $3(n=13)$ & $P$-value \\
\hline $\mathrm{PaCO}_{2}$ higher $(\mathrm{mmHg})$ & $4 I \pm 14$ & $37 \pm 10$ & $39 \pm 6$ & 0.575 \\
\hline $\mathrm{PaO}_{2}$ lower $(\mathrm{mmHg})$ & $67 \pm 27$ & $118 \pm 84 * * *$ & $63 \pm 14$ & 0.009 \\
\hline $\mathrm{SaO}_{2}$ lower (\%) & $82 \pm 16^{*}$ & $93 \pm 6$ & $90 \pm 8$ & 0.026 \\
\hline Serum lactate higher (mmol/L) & $8.8 \pm 6.6^{* *}$ & $6.6 \pm 4.3$ & $2.7 \pm 1.9$ & 0.005 \\
\hline Kirby Index lower $(\mathrm{mmHg})$ & $93 \pm 73 *$ & $167 \pm 88$ & $125 \pm 82$ & 0.046 \\
\hline $\mathrm{O}_{2} \mathrm{~A}-\mathrm{a}$ gradient $(\mathrm{mmH})$ & $368 \pm 133 *$ & $282 \pm 153$ & $309 \pm 166$ & 0.264 \\
\hline Shunts higher (\%) & $39 \pm 16$ & $25 \pm 11$ & $27 \pm 12$ & 0.014 \\
\hline Mechanical ventilation & $12(70.6)$ & II (6I.I) & $5(27.8)$ & 0.028 \\
\hline
\end{tabular}

Notes: Data are expressed as mean \pm standard deviation or $n(\%)$. $* p<0.05$ versus Group 2; ** $p<0.05$ versus Group 3 ; *** $p<0.05$ versus Group 3 .

Abbreviations: $\mathrm{A}-\mathrm{a}$, alveolar-arterial; $\mathrm{O}_{2}$, oxygen; $\mathrm{PaCO}_{2}$, carbon dioxide arterial pressure; $\mathrm{PaO}_{2}$, oxygen arterial pressure; SaO${ }_{2}$, oxygen saturation.

is also detected in association with other cardiac conditions such as acute myocardial infarction, pulmonary embolism, and cardiac tamponade. In patients admitted for cardiogenic shock, the severity of hypotension and a decrease in cardiac output can be related to the development of HH. ${ }^{2}$ However, the incidence of cardiogenic shock and its correlation with HH have not been defined. In the current study, we found that hemodynamic instability characterized the group of patients who developed HH. Their main features were lower mean arterial pressure, systolic pressure, and vascular resistance.

Shock is one of the most frequent conditions associated with the development of $\mathrm{HH}$, and septic shock is involved most often. ${ }^{2,3}$ This association was confirmed in the present study; however, because our study was performed in a cardiac intensive care unit, we found that cardiogenic shock was the predominant type of shock involved.

The use of vasopressors is associated with the development of HH, which may result from hypoxia reperfusion with deleterious effects on hepatic blood flow. ${ }^{4}$ In our study, phenylephrine and norepinephrine were related to the development of $\mathrm{HH}$, confirming this relationship. Another hemodynamic factor crucial to the pathophysiological mechanisms of $\mathrm{HH}$ is passive congestion of the liver secondary to right heart failure. ${ }^{5}$ This was confirmed in our study by the significantly higher CVP and lower TAPSE score in the
HH group compared with the other groups. This may reflect right ventricular overload and impaired function. We note that other values, such as the myocardial performance index, better reflect the overall performance of the right ventricle; however, TAPSE is the most cited variable for the evaluation of right ventricular function. ${ }^{12}$

Respiratory failure is the second most frequent cause of $\mathrm{HH}$ and is responsible for $7 \%-15 \%$ of cases. ${ }^{2,13}$ Hypoxia is the main hemodynamic factor in the development of $\mathrm{HH}$ in respiratory failure. We found that patients with $\mathrm{HH}$ had a greater need for mechanical ventilation (61.1\% compared with $27.8 \%$ in the control group) and worse oxygenation parameters such as lower $\mathrm{PaO}_{2}, \mathrm{SaO}_{2}$, and increased shunts. All of these variables support the idea that respiratory failure is associated with $\mathrm{HH}$ when coupled with an environment of heart disease.

Two prior studies ${ }^{2,4}$ described acute kidney failure as an aid in diagnosing patients with $\mathrm{HH}$ because acute kidney failure is an outcome of hemodynamic disturbances that characterize this set of patients, and its presence is unusual in viral or drug-induced hepatitis. One study reported kidney failure to be an independent risk factor for mortality. ${ }^{14}$ In our study, kidney failure and renal replacement therapy were not associated with the development of HH or with mortality. However, the previous series ${ }^{2,4}$ included patients in worse clinical condition than those in our study.

Table 5 Evaluation of renal function by group

\begin{tabular}{|c|c|c|c|c|}
\hline & Group I $(n=\mid 8)$ & Group $2(n=18)$ & Group $3(n=18)$ & $P$-value \\
\hline \multirow[t]{2}{*}{ Baseline blood urea nitrogen $(\mathrm{mg} / \mathrm{dL})$} & $37 \pm 27$ & $24 \pm 14$ & $35 \pm 47$ & 0.420 \\
\hline & $27.4(11.5-108.6)$ & $17.9(9.7-45.5)$ & $17.75(|0.6-2| 4.4)$ & \\
\hline \multirow[t]{2}{*}{ Highest blood urea nitrogen $(\mathrm{mg} / \mathrm{dL})$} & $4 I \pm 26$ & $28 \pm 18$ & $48 \pm 52$ & 0.221 \\
\hline & $30.55(14-108.6)$ & $22.6(9.7-70.5)$ & $24.4(|0.6-2| 4.4)$ & \\
\hline \multirow[t]{2}{*}{ Baseline creatinine (mg/dL) } & $2.9 \pm 4.9$ & $1.4 \pm 0.9$ & $1.9 \pm 2.6$ & 0.412 \\
\hline & $1.22(0.8-21.76)$ & $1.19(0.66-4.52)$ & $1.175(0.64-12.32)$ & \\
\hline \multirow[t]{2}{*}{ Highest creatinine (mg/dL) } & $2.9 \pm 4.8$ & $1.7 \pm 1.3$ & $2.4 \pm 2.9$ & 0.522 \\
\hline & $1.45(0.8-2 \mid .7)$ & $1.3(0.78-6.28)$ & $1.19(0.72-12.32)$ & \\
\hline Dialysis n (\%) & $4(22.2)$ & $2(11.8)$ & $3(17.6)$ & 0.715 \\
\hline
\end{tabular}

Note: Data expressed as mean \pm standard deviation, median (minimum-maximum), or $n(\%)$. 
Table 6 Clinical features according to mortality

\begin{tabular}{|c|c|c|c|}
\hline Clinical feature & $\begin{array}{l}\text { Survived } \\
(n=36)\end{array}$ & $\begin{array}{l}\text { Died } \\
(n=I 8)\end{array}$ & P-value \\
\hline Shock state & $20(55.6)$ & $18(100)$ & 0.001 \\
\hline Cardiogenic shock & $16(44.4)$ & $15(83.3)$ & \\
\hline Septic shock & $2(5.6)$ & I (5.6) & 0.009 \\
\hline Mixed shock & $2(5.6)$ & $2(I I . I)$ & \\
\hline Use of dopamine & II (30.6) & $8(44.4)$ & 0.239 \\
\hline Use of norepinephrine & $20(55.6)$ & $17(94.4)$ & 0.003 \\
\hline Use of vasopressin & $12(33.3)$ & $15(83.3)$ & 0.001 \\
\hline Use of adrenaline & $3(8.3)$ & $6(33.3)$ & 0.029 \\
\hline Use of levosimendan & $20(55.6)$ & $13(72.2)$ & 0.188 \\
\hline Use of phenylephrine & $4(1 \mathrm{I} .1)$ & 7 (38.9) & 0.023 \\
\hline Use of dobutamine & $4(11.1)$ & 0 & 0.186 \\
\hline Use of intra-aortic balloon pump & I (2.8) & $9(50)$ & 0.001 \\
\hline Mechanical ventilation & $13(36.1)$ & $15(88.2)$ & 0.001 \\
\hline Dialysis & $4(1 \mid .8)$ & $5(27.8)$ & 0.143 \\
\hline
\end{tabular}

Note: Data are expressed as n (\%).

The prognosis of $\mathrm{HH}$ is poor, and more than half of patients will die during their stay in, or shortly after their discharge from the intensive care unit. The five largest series on $\mathrm{HH}$ reported mortality rates ranging from $45 \%$ to $72 \%{ }^{2}$ The mortality rate was $56 \%$ in our study, a rate that is within this range. The factors associated with increased mortality in $\mathrm{HH}$ patients were preexisting liver disease, cardiogenic or septic shock, use of vasopressors (vasopressin, epinephrine, or norepinephrine), and the need for mechanical ventilation. All of these reflect circulatory collapse and respiratory failure. None of the diagnoses at baseline were related to mortality. Acute coronary syndrome in association with heart failure ${ }^{4,7}$ was the most common diagnosis in our series, but it was not related to the incidence of, or mortality from, $\mathrm{HH}$. Other important outcomes measured were days of hospital stay and days within the cardiac intensive care unit, which did not differ between groups.

Henrion et $\mathrm{al}^{5}$ studied high-risk patients in a cardiac intensive care unit and reported a prevalence of $2.6 \%$ in 766 patients; $21.9 \%$ of these patients exhibited low cardiac output, which was double the percentage found in our series. They compared hepatic blood flow by galactose clearance and hemodynamic variables between patients with low cardiac output and $\mathrm{HH}$ and those with low cardiac output without $\mathrm{HH}$. HH was frequent in patients with low cardiac output admitted to the cardiac intensive care unit. In our study, we included all patients admitted to the cardiac intensive care unit, not only high-risk patients. We also found a higher CVP in the $\mathrm{HH}$ group. Hepatic flow was not measured directly, but we obtained an indirect indication of right heart failure, which reflects passive hepatic venous congestion, by measuring TAPSE, which was lower in patients who developed $\mathrm{HH}$.
Our study is the first to include an intermediate group of patients (Group 2) with altered liver function who do not meet the criteria for $\mathrm{HH}$. This particular group had more cardiogenic shock events than the HH group, although the difference was not significant. Group 2 also showed a worse hemodynamic profile, with lower cardiac index and cardiac output. There was a slight tendency toward increased mortality in patients who met the HH criteria, being high (35.3\%). Thus, it is important to pay attention to patients with cardiogenic shock who do not meet all the $\mathrm{HH}$ criteria. More research is needed on this forgotten group of patients.

\section{Limitation of the study}

First, the present study had a retrospective design, and limited information could be obtained. However, our results are similar to those of the only prospective study on this topic. ${ }^{8}$ Second, our sample was small, and this may have affected our ability to detect some relationships between outcomes such as an association with kidney failure, which has been reported in other studies. ${ }^{2,4}$ Third, we did not use a direct method to measure hepatic blood flow.

\section{Conclusion}

In conclusion, $\mathrm{HH}$ is an uncommon condition in patients admitted to the cardiac intensive care unit, but it has a high mortality rate. Cardiogenic shock is an important cause of $\mathrm{HH}$. Mechanical ventilation and the use of vasopressors are independent risk factors for the development of $\mathrm{HH}$. Patients with abnormal liver function who do not meet the criteria for $\mathrm{HH}$ may have an unclear prognosis, and further research is needed to clarify the clinical course in this group of patients.

\section{Acknowledgment}

This study was partially supported by an educational grant from Medica Sur Clinic and Foundation.

\section{Author contributions}

OGC developed the idea for this study. NCCT developed the idea for this study, performed literature search, analyzed data, and wrote the manuscript. PMM, BVBG, MHG, and SGL collaborated to design the protocol, performed literature search, analyzed data, and reviewed and edited the manuscript. MU reviewed the manuscript. All authors have approved the final version of this article, including the authorship list.

\section{Disclosure}

The authors report no conflicts of interest in this work. 


\section{Key messages}

- Cardiogenic shock was the predominant type of shock involved with the development of $\mathrm{HH}$ in cardiac intensive care unit.

- Mechanical ventilation is an independent risk factor to the development of $\mathrm{HH}$.

- Those patients with altered liver function tests who do not meet criteria for $\mathrm{HH}$ should be followed carefully.

\section{References}

1. Henrion J, Schapira M, Luwaert R, Colin L, Delannoy A, Heller FR. Hypoxic hepatitis: clinical and hemodynamic study in 142 consecutive cases. Medicine (Baltimore). 2003;82(6):392-406.

2. Henrion J. Hypoxic hepatitis. Liver Int. 2012;32(7):1039-1052.

3. Fuhrmann V, Kneidinger N, Herkner H, et al. Hypoxic hepatitis: underlying conditions and risk factors for mortality in critically ill patients. Intensive Care Med. 2009;35(8):1397-1405.

4. Fuhrmann V, Kneidinger N, Herkner H, et al. Impact of hypoxic hepatitis on mortality in the intensive care unit. Intensive Care Med. 2011;37(8): 1302-1310.

5. Henrion J, Descamps O, Luwaert R, Schapira M, Parfonry A, Heller F. Hypoxic hepatitis in patients with cardiac failure: incidence in a coronary care unit and measurement of hepatic blood flow. J Hepatol. 1994;21(5): 696-703.
6. Myers RP, Cerini R, Sayegh R, et al. Cardiac hepatopathy: clinical, hemodynamic, and histologic characteristics and correlations. Hepatology. 2003;37(2):393-400.

7. Pinsky MR. Functional hemodynamic monitoring. Intensive Care Med. 2002;28(4):386-388.

8. Vignon P. Hemodynamic assessment of critically ill patients using echocardiography Doppler. Curr Opin Crit Care. 2005;11(3): 227-234.

9. McCullough PA, Nowak RM, McCord J, et al. B-type natriuretic peptide and clinical judgment in emergency diagnosis of heart failure: analysis from Breathing Not Properly (BNP) Multinational Study. Circulation. 2002;106(4):416-422.

10. Shneerson JM. Techniques in mechanical ventilation: principles and practice. Thorax. 1996;51(7):756-761.

11. Bailie GR, Uhlig K, Levey AS. Clinical practice guidelines in nephrology: evaluation, classification, and stratification of chronic kidney disease. Pharmacotherapy. 2005;25(4):491-502.

12. Burgess MI, Bright-Thomas RJ, Ray SG. Echocardiographic evaluation of right ventricular function. Eur $J$ Echocardiogr. 2002;3(4): 252-262.

13. Raurich JM, Llompart-Pou JA, Ferreruela M, et al. Hypoxic hepatitis in critically ill patients: incidence, etiology and risk factors for mortality. J Anesth. 2011;25(1):50-56.

14. Raurich JM, Pérez O, Llompart-Pou JA, Ibáñez J, Ayestarán I, PérezBárcena J. Incidence and outcome of ischemic hepatitis complicating septic shock. Hepatol Res. 2009;39(7):700-705.
Therapeutics and Clinical Risk Management

\section{Publish your work in this journal}

Therapeutics and Clinical Risk Management is an international, peerreviewed journal of clinical therapeutics and risk management, focusing on concise rapid reporting of clinical studies in all therapeutic areas, outcomes, safety, and programs for the effective, safe, and sustained use of medicines. This journal is indexed on PubMed Central, CAS,

\section{Dovepress}

EMBase, Scopus and the Elsevier Bibliographic databases. The manuscript management system is completely online and includes a very quick and fair peer-review system, which is all easy to use. Visit $\mathrm{http}: / / \mathrm{www}$.dovepress.com/testimonials.php to read real quotes from published authors. 